\title{
A LITERATURE ANALYSIS OF THE RELATIONSHIP BETWEEN FAIR VALUE ACCOUNTING AND EARNINGS MANAGEMENT
}

DOI: $10.17261 /$ Pressacademia.2021.1472

JEFA- V.8-ISS.4-2021(3)-p.174-183

Deniz Ozbay

Maltepe University, Faculty of Business and Management Sciences, Istanbul, Turkey.

denizozbay@maltepe.edu.tr, ORCID: 0000-0003-4643-7577

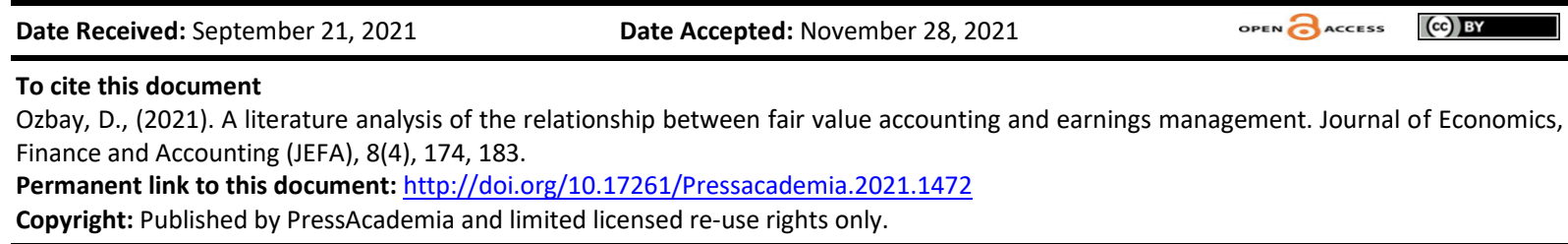

\section{ABSTRACT}

Purpose- The main purpose of the financial statements is to provide timely, accurate and reliable information to the users of the financial statements during their decision process. The valuation method of financial assets and liabilities causes significant changes in the results of the financial statements. Although fair value is the most desired valuation method there are some criticisms in the literature that the fair value approach may use as an earning management tool. The purpose of this study is to analyze the findings of previous studies which empirically analyze the relationship between fair value measurement and earnings management and to make contribution to the literature which investigates the utility of the fair value accounting.

Methodology- In the study, the findings of 25 empirical studies which examined the relationship between fair value measurement and earnings management that indexed in the Web of Science database in the last ten years (2012-2021) were analyzed and interpreted under different classifications such as sample, variables used and the direction of the relationship.

Findings- According to the results of the studies under review, with the transition to fair value measurement, earnings management practices have decreased predominantly. On the other hand, using level 3 inputs for fair value measurement has increased earnings management. Conclusion- With the effect of changes in accounting standards, the use of fair value in the valuation of assets and liabilities is increasing. However, level 3 inputs are unobservable and largely available to management discretion, bias, and opportunism. The results of the study reveal once again that the importance of maximizing the use of relevant observable inputs and minimizing the use of unobservable inputs.

Keywords: Fair value, earnings management, IFRS 13, fair value hierarchy, literature analysis.

JEL Codes: M40, M41, M48

\section{GERÇEĞE UYGUN DEĞER íLE KAZANÇ YÖNETiMi ARASINDAKi iLişKININ LiTERATÜR ANALIZi íL INCELENMESI}

\section{ÖZET}

Amaç- Finansal tabloların temel amacı, finansal tablo kullanıcılarına karar sürecinde kullanacakları zamanında, gerçek ve güvenilir bilgilerin sunulmasıdır. Finansal varlık ve yükümlülüklerin değerleme metodu finansal tabloların sonuçlarında önemli değişikliklere neden olmaktadır. Gerçeğe uyun değer en çok tercih edilen değerleme metodu olmasına ragmen, literatürde gerçeğe uygun değer yaklaşımının kazanç yönetimi aracı olarak kullanıldığı yönünde bazı eleştiriler bulunmaktadır. Bu çalışmanın amacı, gerçeğe uygun değer ölçümü ve kazanç yönetimi arasındaki ilişkiyi ampirik olarak inceleyen geçmiş çalışmaların bulgularını analiz etmek ve gerçeğe uygun değerin yararlılı̆ını araştıran literatüre katkı sağlamaktır.

Yöntem- Çalışmada, son on yıllık dönemde (2012-2021) gerçeğe uygun değer ölçümü ve kazanç yönetimi arasındaki ilişkiyi ampirik olarak inceleyen ve Web of Science veri tabanında endekslenen 25 ampirik çalışmanın bulguları örneklem, kullanılan değişkenler ve ilişkinin yönü gibi farklı sınıflandırmalar altında incelenmiş ve yorumlanmıştır.

Bulgular- İncelenen çalışmaların sonuçlarına göre, gerçeğe uygun değer ölçümüne geçiş ile birlikte kazanç yönetimi uygulamalarının ağırlıklı olarak azaldığıdı görülmektedir. Öte yandan, gerçeğe uygun değer ölçümünde seviye 3 girdilerinin kullanımı kazanç yönetimini arttırmaktadır. Sonuç- Varlık ve yükümlülüklerin değerlemesinde gerçeğe uygun değer kullanımı, muhasebe standartlarında yapılan değişikliklerin etkisi ile giderek artmaktadır. Seviye 3 girdileri, gözlemlenemeyen girdiler oldukları için yoğun olarak yönetimin takdirine, yanlılığına ve fırsatçılığına açıktır. Çalışma sonuçları, gerçeğe uygun değer hesaplamasında seviye 3 kullanımının mümkün olan en az düzeyde olması gerekliliğini bir kez daha ortaya koymaktadır.

Keywords: Gerçeğe uygun değer, kazanç yönetimi, TFRS 13, gerçeğe uygun değer hiyerarşisi, literatür analiz JEL Codes: M40, M41, M48 


\section{GiRiş}

Finansal tabloların amacı, tablo kullanıcılarına gerçeğe en uygun ve güvenilir bilgiler sunmaktır. Özellikle son yüzyılda yaşanan gelişmeler ve şirket skandalları güvenilir bilgiye olan ihtiyacı daha da arttırmıştır. Varlık ve yükümlülüklerin değerleme yöntemleri, finansal tablolarda raporlanan tutarları önemli ölçüde etkilemektedir. Bu durum yöneticiler, hissedarlar, yatırımcılar, kredi verenler ve devlet gibi farklı finansal tablo kullanıcıların karar alma süreçlerini de yakından etkilemektedir. Gerçeğe uygun değer ölçümü bu amaca en iyi hizmet eden değerleme yöntemi olarak görülmekte olup muhasebe standartlarında geniş bir yer bulmaktadır.

Gerçeğe uygun değer ölçümü Uluslararası Finansal Raporlama Standardı (IFRS) 13'te düzenlenmiştir. Standart, gerçeğe uygun değer ölçümünde kullanılan girdileri üç seviyede toplamaktadır. Seviye 1 ve seviye 2 girdileri gözlemlenebilir girdilerken, seviye 3 girdileri ise gözlemlenemeyen, başka bir ifadeyle doğruluğu emsal bir varlık ya da yükümlülükle teyit edilemeyen girdilerden oluşmaktadır. Gerçeğe uygun değer tespitinin gözlemlenebilir girdilerin olmaması durumunda yoğun tahmine dayanması, ölçümünün karışık ve zor olması ve manipülasyona açık olması nedeniyle ölçümün gerçeği yansıtmayabileceği yönünde önemli eleştiriler bulunmaktadır. Gerçeğe uygun değer ölçümünün bu tartışmalı özellikleri nedeniyle kazanç yönetimi ile ilişkisi araştırmacıların yoğun ilgisini çekmektedir. Literatür incelendiğinde gerçeğe uygun değerin kazanç yönetimini teşvik ettiği ya da azalttığı yönünde birbirinden çok farklı görüşler olduğu ve ampirik çalışmaların sonuçlarının da ilişkinin yönünü net bir şekilde ortaya koyamadığı görülmektedir. Bu çalışma kapsamında, varlık/yükümlülüklerin değerlemesinde gerçeğe uygun değer kullanımının ve ayrıca gerçeğe uygun değer hiyerarşisinin kazanç yönetimi üzerindeki etkisinin literatür taraması vasıtasıyla araştırılması amaçlanmaktadır.

Çalışmada öncelikle gerçeğe uygun değer kavramı açıklanmış, gerçeğe uygun değer muhasebesine olan ihtiyacın nedenlerine ve değer ölçümünün nasıl ve hangi girdilerin kullanımı ile yapıldığına yer verilmiştir. İzleyen bölümde kazanç yönetimi kavramı ve kazanç yönetimi uygulama teknikleri açıklanmıştır. Daha sonra, gerçeğe uygun değer ve kazanç yönetimi arasındaki ilişkiyi konu alan çalışmalar incelenmiştir. Son olarak, çalışma kapsamında incelenen ampirik araştırmaların bulguları incelenerek yorumlanmıştır.

\section{GERÇEĞE UYGUN DEĞER MUHASEBESI}

Gerçeğe uygun değer kavramının İngilizce'deki karşılığı "fair value” terimidir. Makul değer ya da rayiç değer gibi kavramlarla da ifade edilen "fair value" kelimesi, Türkiye Finansal Raporlama Standartları (TFRS) kapsamında gerçeğe uygun değer olarak kullanılmaktadır. Gerçeğe uygun değer, gerçek değeri değil, bir finansal varlığın ya da yükümlülüğün piyasa şartlarında olabileceği en gerçeğe yakın değeri ifade etmektedir. Varlık ve yükümlülükler ilk kayda alınmalarında maliyet bedeliyle ölçülmektedir. Ancak şirketlerin finansal durum tablosundaki varlıklarının maliyet değerleri güncel değerlerini yansıtma konusunda oldukça yetersiz kalmaktadır (Cebeci ve Gökçen, 2019, s.197). Bu nedenle muhasebe standartlarında varlık ve borçların gerçeğe uygun değeriyle ölçülmesi ve finansal tablolarda raporlanmasının, finansal tablo kullanıcılarının bilgi ihtiyacının karşılanması için önemli olduğu ifade edilmektedir (Gökgöz ve Şentürk, 2015, s.70).

Gerçeğe uygun değer kavramı 1980'li yıllardan itibaren muhasebe literatüründe yer alamaya başlamış olmakla birlikte, ilk defa 2006 yılında Amerikan Muhasebe Standartları Kurulu (Financial Accounting Standards Board - FASB) tarafından, SFAS 157 Gerçeğe Uygun Değer Ölçümleri (Fair Value Measurements) yayımlanmıştır (Senel vd., 2011, s. 60). Bu standarttan önce ise farklı standartlar içinde gerçeğe uygun değer ölçümüne yer verilmiştir. Uluslararası Muhasebe Standartları Kurulu (International Accounting Standard Board - IASB), 12.05.2011 tarihinde IFRS "Gerçeğe Uygun Değer Ölçümü" standardını yayımlamıştır. Buna paralel olarak, TFRS 13 “Gerçeğe Uygun Değer Ölçümü" standardı, 30.12.2012 tarih ve 28513 sayılı resmî gazetede yayımlanmış ve 31.12.2012 tarihinden sonra başlayan hesap dönemlerinde uygulanmaya başlanmıştır.

TFRS 13 gerçeğe uygun değeri, "piyasa katılımcıları arasında ölçüm tarihinde olağan bir işlemde, bir varlığın satışından elde edilecek veya bir borcun devrinde ödenecek fiyat olarak" tanımlanmaktadır (TFRS 13, para.9). Gerçeğe uygun değer, tahmini bir fiyatı ifade etmektedir. Bu tahmin bazı durumlarda gözlemlenebilir girdiler ile gerçekleşirken, bazı durumlarda da gözlemlenemeyen girdiler ile hesaplanmaktadır. Örneğin aktif bir piyasası bulunan ya da kendisine özdeş bir varlığın aktif bir piyasası bulunan varlıkların ölçümünde gerçeğe uygun değeri hesaplamak nispeten çok daha kolay olmaktadır. Ama bazı varlıklar için etkin bir piyasa bulunmadığı gibi, özdeş bir varlık ile ölçülmesi de sor olabilir. Bu durumda kullanılan girdiler gözlemlenebilir olmayan girdiler olarak ifade edilmekte ve yoğun tahmin içermektedir. Bu nedenle, gözlemlenebilir girdilerin kullanımını azami seviyeye çıkarmak ve gözlemlenebilir olmayan girdilerin kullanımlarını ise asgari seviyede tutmak temel prensiptir (TFRS 13, para.61).

Gerçeğe uygun değerin, gerçeğe en yakın haliyle hesaplanması için, hesaplamada kullanılan girdilerin, mümkün olan en yüksek düzeyde gözlemlenebilir girdilerden oluşması gerekmektedir. TFRS 13, gerçeğe uygun değer ölçümünde kullanılan girdileri üç seviye altında, aşağıdaki gibi tanımlanmaktadır (TFRS 13, para. Ek A):

Seviye 1 girdileri: İşletmenin ölçüm tarihinde erişebileceği, özdeş varlıkların veya borçların aktif piyasalardaki kotasyon fiyatları. 
Seviye 2 girdileri: Varlığa veya borca ilişkin doğrudan veya dolaylı şekilde gözlemlenebilir olan, Seviye 1 içerisindeki kotasyon fiyatları dışındaki girdiler.

Seviye 3 girdileri: Varlığa veya borca ilişkin gözlemlenebilir olmayan girdiler.

Gözlemlenebilir girdiler, seviye 1 ve seviye 2 girdileridir. Bir varlık ya da yükümlülük aktif bir piyasa işlem görüyorsa (kotasyon fiyatı varsa) seviye 1 kapsamında raporlanır. Varlık ya da yükümlülüğün kote edilmiş bir fiyatı olmamakla birlikte, kendisini yansıtan, benzer (özdeş) varlık/yükümlülüklerin aktif olan ya da olmayan bir piyasada kotasyon fiyatı bulunuyorsa, bu fiyat seviye 2 kapsamında raporlanmaktadır. Ancak hem iç hem de dış veriler yardımıyla fiyat tahmini yapılıyorsa, hesaplanan fiyat diğer piyasa verileriyle tutarlı ise seviye 2; değil ise seviye 3 kapsamında raporlanmaktadır (Camphell, vd., 2008, s. 34). Gözlemlenebilir girdiler, halka açık piyasa verileri kullanılarak hesaplanmaktadır. Borsalar, satıcı piyasaları, aracılı ve aracısız piyasalar gözlemlenebilir girdilere, yani seviye 1 girdilerine örnek olarak verilebilir. Bunun yanında, işletmenin kira geliri amacıyla edindiği yatırım amaçlı gayrimenkulü değerlemede, varlığın ömrü süresince elde edilecek net nakit akışlarının bugünkü değerine indirgenme yönteminin kullanımı ise seviye 3 girdilerine örnek teşkil etmektedir. (Gökgöz ve Şentürk, 2015, s. 71-72).

TFRS 13 kapsamında yapılan seviye sıralaması, tahminlerde kullanılan farklı girdilerle ilişkili belirsizlik ve güvenilirik düzeyine dayanmaktadır (Ghio, vd., 2018, s. 2). Seviye 1 girdileri en güvenilir girdilerken, seviye 3 girdileri çok fazla tahmin ve belirsizlik içermesi ve dolayısıyla güvenilebilirliğinin düşük olması gerekçesi ile eleştirilmektedir. Hsu ve Wu (2019, s. 45), gerçeğe uygun değer ölçümündeki problemleri şu şekilde özetlemektedir:

(1) Çoğu varlık ve yükümlülük için etkin bir piyasa bulunmamaktadır, dolayısıyla gerçeğe uygun değer tahminlerinin kullanımı oldukça subjektif ve güvenilirlikten uzak olmaktadır.

(2) Gerçeğe uygun değerdeki değişikliklerden kaynaklanan gerçekleşmemiş kazançlar veya kayıplar gelir tablosunda muhasebeleştirildiği için, bu durum kazanç dalgalanmalarına ve tahmin güçlüklerine neden olmaktadır.

(3) Tahmine dayalı gerçeğe uygun değer, yöneticilerin manipülasyonuna daha fazla açıktır.

Yaygın olarak kullanılan üç değerleme yöntemi bulunmaktadır. Bunlar; piyasa yaklaşımı, maliyet yaklaşımı ve gelir yaklaşımıdır. İşletme, gerçeğe uygun değeri ölçmek için bu yaklaşımların bir veya birkaçı ile tutarlı olan değerleme yöntemlerini kullanır (TFRS 13, para.62).

Piyasa yaklaşımında, varlığın ya da borcun değerlemesi, benzer bir varlık ya da borcun veya varlık-borç grubunun piyasa fiyat bilgilerinin kullanımıdır. Matris fiyatlaması piyasa yaklaşımı içinde kullanılabilecek değerleme yöntemlerinden biridir. Bazı finansal araçların değerlemesinde kullanılan bu yöntemde finansal varlığın değeri, kotasyon fiyatı bulunan benzer finansal varlıklar ile olan ilişkiye dayanarak ölçülür (TFRS 13, para.B5-B7). Maliyet yaklaşımı ise bir varlığın yenileme maliyeti olarak adlandırılır. Daha çok maddi duran varlıkların değerlemesinde kullanılır (TFRS 13, para.B8-B9). Gelir yaklaşımı, gelecekteki nakit akışları veya gelir ve giderleri, iskonto edilmiş güncel bir fiyata çeviren yöntemleri içermektedir. Bugünkü değer yaklaşımı, opsiyon fiyatlama modelleri ya da artık kazanç yöntemi gelir yaklaşımına örnek olarak verilebilecek hesaplama yöntemleridir (TFRS 13, para.B10-B11).

\section{KAZANÇ YÖNETIMI}

Kazanç yönetimi, yöneticilerin kendi hedefleri ya da çıkarları doğrultusunda, finansal tabloları olduğundan daha farklı göstermek üzere, kazanç üzerinde yaptıkları değişikliklerdir. Kazanç yönetimi yasal sınırlar içinde olmakla birlikte, isteğe bağlı olarak finansal tabloların manipüle edilmesidir. Literatürde çok sayıda kazanç yönetimi tanımı bulunmakla birlikte, tanımların birbirini desteklediği görülmektedir. Schipper'in $(1989$, s. 92) tanımına göre kazanç yönetimi, özel kazançlar elde etmek amacıyla finansal raporlamaya kasıtlı yapılan müdahaleler olup, ifşa yönetimi olarak tanımlanmaktadır. Levitt (1998) ise kazanç yönetimi kapsamında raporlanan kazançların, gerçek finansal performanstan ziyade yönetimin isteklerini yansıttı̆̆ı vurgusu yapmaktadır. (Levitt, 1998, s. 14-19). Healy ve Wahlen (1999) kavramı daha geniş kapsamlı olarak ele almıştır. Onların tanımına göre kazanç yönetimi, bazı çıkar sahiplerini firmanın finansal performansına ilişkin yanıltmak veya finansal raporlamaya bağlı olarak değişen sözleşmelerin sonuçlarını etkimek amacıyla, yöneticiler tarafından finansal raporlarda sunulan kazançların değiştirilmesidir (Healy ve Wahlen, 1999, s. 368). Dechow ve Skinner (2000), kazanç yönetiminin kapsamını kasti kazanç değişiklikleri yanında, hiç açıklanmayan ya da yetersiz açıklanan kazançları da kapsayacak şekilde genişletmiştir (Dechow ve Skinner, 2000, s. 238).

Kazanç yönetimi, muhasebe politikalarının seçimi, alınan kararlarla işletme faaliyetlerinin düzeyinin değiştirilmesi veya gelir ve giderlerin olduğundan farklı sınıflandırılması olmak üzere farklı şekillerde olabilmektedir. Literatürde kazanç yönetimi teknikleri üçe ayrılmaktadır (Adıgüzel, 2018, s. 64):

(1) Tahakkuk yönetimi,

(2) Faaliyetlerin yönetimi, 


\section{(3) Sinıflandırma}

Tahakkuk yönetimi (accrual-based earnings management) kapsamında toplam tahakkuk modeli, belirli bir tahakkuk üzerinde yoğunlaşan modeller ve gelirin bir eşikte toplanmasını ölçen modeller olarak üç farklı model bulunmaktadır (Adıgüzel, 2018, s. 65). Kazanç yönetiminin ölçülmesine ilişkin yapılan çalışmaların önemli bölümünde toplam tahakkuklar kullanılmıştır. Tahakkuklar, ihtiyari olan ve olmayan olmak üzere iki başlık altında değerlendirilmektedir. Ihtiyari olmayan tahakkuklar normal faaliyetlerle ilgilidir. Kazanç yönetiminin konusunu ise yöneticilerin takdir yetkisine dayanan ihtiyari tahakkuklar oluşturmaktadır. Bunlar Anormal ya da beklenmeyen tahakkuklar olarak da adlandırılmaktadır (Bartov, vd., 2002, s. 196). Toplam tahakkuk modelleri arasında ilk olmamakla birlikte en yaygın olarak kullanılan model Jones (1991) tarafından geliştirilmiştir. Geçmiş modellerin kapsamını geliştiren bu modelde ihtiyari olmayan tahakkukların tahmininde zaman serisi modelleri geliştirilmiştir. Modelde kazanç yönetimini hesaplamak için ilk olarak firma özelliklerine göre olması gereken tahakkuklar belirlenmekte, sonra gerçekleşen tahakkuklar ile olması gereken tahakkuklar arasındaki fark hesaplanmaktadır. Bu fark kasıtlı olarak fazladan ayrılan tahakkuk olarak değerlendirilmektedir (Jones, 1991, s. 206-207). Dechow, vd. (1995), Jones'un (1991) modelini, hasılatın kasıtlı tahakkukları içermediği varsayımı nedeniyle eleştirmiş ve bu modele ticari alacaklardaki değişimi de ekleyerek yeni bir model önerisinde bulunmuştur. Kazanç yönetimini toplam tahakkuklar yerine tek bir tahakkuk üzerinde yoğunlaşarak ölçen çalışmalar da mevcuttur. Örneğin bankalar üzerinde yapılan birçok çalışmada, ihtiyari kredi kazanç karşılıkları, kazanç yönetimi göstergesi olarak kullanılmaktadır (Xu, 2019; Zhao, 2019; Chen, vd., 2020). Gelirin belirli bir eşik etrafında toplanması modellerinde ise, gelire ilişkin algı yaratmaya dönük teknikler ifade edilmektedir. Örneğin Degeorge, vd. (1999), üç eşikten bahsetmektedir. Bunlardan biri negatif kazanç beyan etmek yerine, sıfır kâr ya da çok küçük bir kâr açıklamanın her zaman daha pozitif algılanacağıdır. İkinci ve üçüncü eşik, ise göreceli performansa göre gelirin raporlanmasıdır. İ̧̧letme ile karşılaştırılabilecek diğer işletme örneklerinin ortalama kazançları ile işletmenin sonuçları karşılaştırılarak, bu ortalamayı aşmayacak ya da çok aşağı çekmeyecek bir kazanç raporlamaya dönük yaklaşımdır (Degeorge, vd., 1999, s. 3).

Faaliyetlerin yönetimi (real earnings management), istenen kâr rakamına ulaşabilmek adına, yöneticilerin işletme faaliyetleri üzerinde yaptıkları değişiklikleri ifade etmektedir. Literatürde faaliyetlerin yönetimi yoluyla yapılan kazanç yönetiminde ağırlıklı olarak şirketlerin kısa vadede rapor edilen kazançlarını artırmak için pazarlama giderlerini azaltmaya başvurdukları görülmektedir (Gandhi, 2018-19, s. 258). Gunny (2010) faaliyetlerin kazanç yönetimi aracı olarak yönetilmesini üç başlık altında toplamaktadır. Bunlar; satışları arttırmak için geçici olarak satış fiyatını azaltmak, sabit maliyetleri azaltmak amacıyla üretim miktarını arttırarak satılan mamul maliyetini azaltmak, ar-ge harcamalarını kısmak olarak sıralanmaktadır (Adıgüzel, 2018, s. 68). Xu, vd. (2007) faaliyet yönetimi literatürünü inceledikleri çalışmalarında en çok kullanılan yöntemleri, işletme ve yatıım faaliyetlerinin yönetimi ve finansman faaliyetlerinin yönetimi olmak üzere iki ana başlık altında toplamıştır. İşletme ve yatırım faaliyetleri isteğe bağı giderler, üretim giderleri, satış hasılatı, uzun vadeli varılık satısı ve yatırımların yapılandırılması konularını kapsamaktadır. Finansal faaliyetler içinde ise finansal araçların yönetimi ve finansal işlemlerin yapılandırılması konuları ön plana çıkmaktadır.

Sınıflandırma yoluyla kazanç yönetimi (classification shifting), gelir ve giderlerin normalde olması gereken sınıf dışında başka bir sınıfta raporlanması ile finansal tablo sonuçlarının değiştirilmesidir. Sınıflandırma yoluyla kazanç yönetimi ilk olarak McVay (2006) tarafından yapılan yöneticilerin olağan faaliyet giderlerini, olağan dışı gider olarak raporlamak suretiyle faaliyet kârlarını değiştirip değiştirmediklerini araştıran bir çalışma ile dikkat çekmiştir. Çalışma sonuçları yöneticilerin yeniden sınıflandırma ile kazanç yönetimi yaptıklarına dair hipotezi doğrulayan bulgulara ulaşılmıştır. Fan, vd. (2010) tarafından yapılan araştırmanın sonuçları da McVay'in (2006) sonuçlarını desteklemiştir. Bu çalışmada ayrıca yöneticilerin belirli muhasebe dönemlerinde ve yönetim takdirine bağlı tahakkuk imkânının daha sınırlı ortamlarda, sınıflandırma yoluyla kazanç yönetiminin arttığına dair kanıtlar elde etmiştir.

Hisse senedi fiyat düşüşlerinden kaçınmak, yönetici primlerini arttırmak, kredi sözleşme şartlarını yerine getirmek (Mulford, vd., 2002, s. 3), üst düzey yöneticiler ile analistlerin beklentilerinin karşılaması (Degeorge, vd., 1999, s.3), borçlanma maliyetlerini düşürmek, kamu ve özel kesimdeki otoritelerin yaptırımlarından korunmak (Demir ve Bahadır, 2007, s.111) gibi nedenlerle işletmeler kazanç yönetimi gerçekleştirmektedir. En çok gerçekleştirilen kazanç yönetimi uygulamalarına; amortisman yönteminin değiştirilmesi, duran varlıklarda hurda değerin ya da ekonomik ömrün değiştirilmesi, şüpheli alacaklar karşılığı, ertelenmiş vergiler üzerinden kazanç yönetimi, yatırımlarda gider tahakkuklarının tahmini, kıdem tazminatında kullanılan tahminlerin değiştirilmesi, türev ürünlerde sınıflandırma değişiklikleri örnek olarak gösterilebilir (Mulford, vd., 2002, s. 65).

\section{GERÇEĞE UYGUN DEĞER MUHASEBESI VE KAZANÇ YÖNETiMi iLişKisi}

Muhasebe standartlarının temel amacı, finansal tablo kullanıcılarına gerçeğe uygun, şeffaf, zamanında ve kaliteli bilgiler sunabilmektir. Gerçeğe uygun değer kavramı da bu amaç doğrultusunda ortaya çıkmıştır. Gerçeğe uygun değeri savunanlar, gerçeğe uygun değer ölçümüyle, tarihi maliyet esasına kıyasla, çok daha fazla gerçek, zamanında ve karşılaştırılabilir tutarların hesaplandığını vurgulamaktadır (Hsu \& Wu, 2019, s. 38). Ancak, gerçeğe uygun değer muhasebesinin uygulanmasında da önemli bazı problemler bulunmaktadır. Eleştiriler özellikle seviye 3 girdilerinin kullanımı üzerinde yoğunlaşmaktadır (Song, 
vd., 2010; Šodan, 2019; Lin, 2021). Seviye 3 girdileri ile hesaplanan gerçeğe uygun değer, tahmine dayalı olduğu için yönetimsel yanlılığa da oldukça açıktır. Gerçeğe uygun değer muhasebesini savunanlardan birçoğu da bu problemi kabul etmekle birlikte, seviye 1 ve seviye 2 girdilerine dayanan hesaplamaların olumlu katkılarına odaklanmayı tercih etmektedirler. Ghio, vd. (2018), IFRS 13 ve SFAS 157 standartlarının uygulanma sonuçlarına yönelik olarak yaptıkları geniş literatür analizinde, seviye 3 girdileri ile yapılan değer tahminlerinin yönetimin fırsatçı yaklaşımlarını içerdiğine vurgu yapmakta, ancak fırsatçı yaklaşımları nedeniyle piyasa tarafından cezalandırılma riskini göze alamayan yöneticilerin zamanla seviye 3'te rapor edilen varlık miktarını en aza indirmek için uğraşacaklarını belirtmektedir (Ghio, vd., 2018, s. 3).

Literatür incelendiğinde, gerçeğe uygun değer ölçümünün kazanç yönetimini teşvik edip etmediğine dair net bir görüş birliğine varılmadığı görülmektedir. Gerçeğe uygun değerin finansal tablo kullanıcılarına, maliyet bedeline kıyasla, çok daha güvenilir bilgiler sağladığı yönündeki görüşler ağırlıklı olmakla birlikte, değer tespitinin tahminlere dayanması, işletme yönetiminin finansal tabloları kendi istedikleri şekilde değiştirme olanağını doğurmaktadır. Değer tespitinde kullanılan seviye 1 girdileri piyasa verilerine dayandığı için güvenilirliği kabul edilmektedir. Ancak etkin bir piyasanın olmadığı durumlarda hesaplanan gerçeğe uygun değer, çok daha zor tahminler ve daha az güvenilir bilgi içerir (Hsu \& Wu, 2019, s. 39). Öte yandan, bazı araştırmaların sonuçları işletmelerin kurumsal yapılarının kazanç yönetimi uygulamalarına yönelme eğilimlerini azalttığını göstermektedir. Benzer şekilde güçlü kurumsal yönetim yapısının, gerçeğe uygun değer ve kazanç yönetimi arasındaki pozitif ilişkinin etkisini hafiflettiği görülmektedir (Hsu ve Lin, 2016; Ghio, vd., 2018; Thesing ve Velte (2021).

Gerçeğe uygun değerin tahmine dayalı ve manipülasyona açık yapısı, finansal tabloların denetimini de zorlaştırmaktadır. Kohlbeck, vd. (2017), finansal araçların değerlemesinde seviye 3 girdilerinin kullanılmasının, yöneticilerin takdir yetkisini fırsatçı bir şekilde kullanma düzeylerinin daha fazla olduğu sonucuna ulaşmıştır. Aynı çalışmada denetçilerin, denetim ücretleri vasıtasıyla seviye 3 girdilerinin kullanımını kısıtlayıp kısıtlamadığı araştııımıştır. Bulgular, denetçilerin Seviye 3 ile ilgili riskleri, hem Seviye 3 sınıflandırmasına geçişi kısıtlayarak hem de geçiş gerçekleştiğinde daha yüksek denetim ücretleri talep ederek yönettiklerini göstermektedir. Goncharov, vd. (2014), Amerika'da gayrimenkul firmaları üzerinde bir araştırma yapmışlar ve gayrimenkullerin değerlemesinde gerçeğe uygun değer yaklaşımını benimseyen firmaların denetim ücretlerinin, maliyet esasına göre çok daha fazla olduğunu tespit etmişlerdir. Bunun nedeni, gayrimenkullerin gerçeğe uygun değerinin belirlenmesinde ve değer düşüklüğü testlerinde kullanılan girdilerin karmaşık yapısı ve yüksek yönetimsel tahmin gerektirdiği için ölçümlerinin zor olmasıdır.

Bu çalışmada, gerçeğe uygun değer ölçümü ve gerçeğe uygun değer hiyerarşisi ile kazanç yönetimi arasındaki ilişkiyi ele alan 25 adet makalenin sonuçları inceleme kapsamına alınmıştır. İncelenen makalelerin seçilmesi için Web of Science veri tabanından yararlanıımıs ve son on yılı kapsayan çalışmalar dikkate alınmıştır. Veri tabanında "earning anagement", "fair value" anahtar kelimeleriyle yapılan ilk taramada 215 çalışma tespit edilmiştir. Bu çalışmalardan sadece makaleler seçildiğinde ise 149 makaleye ulaşılmıştır. Bu makalelerden ampirik olan ve gerçeğe uygun değer muhasebesi ve kazanç yönetimi arasındaki ilişkiyi doğrudan araştıran 25 makale tespit edilmiştir. İncelenen makaleler ve bulgularına Tablo 1'de yer verilmiştir.

Tablo 1: İncelenen Ampirik Çalışmalar ve Sonuçları

\begin{tabular}{|l|l|l|l|l|l|}
\hline Kaynak & Yıl & Örneklem/Veri Seti & Bağımlı Değişken & Bağımsız Değişken & Sonuç \\
\hline Cheng & 2012 & $\begin{array}{l}886 \text { banka, 1531 } \\
\text { veri, 2006-2020 }\end{array}$ & $\begin{array}{l}\text { GUD rasyosu (GUD/itfa edilen } \\
\text { maliyetler) }\end{array}$ & $\begin{array}{l}\text { Gerçeğe uygun } \\
\text { değer (GUD) } \\
\text { uygulanması }\end{array}$ & Pozitif \\
\hline $\begin{array}{l}\text { He, Wong ve } \\
\text { Young }\end{array}$ & 2012 & 786 veri, 2007-2008 & $\begin{array}{l}\text { Toplam varlıklarla ölçülen } \\
\text { anormal kazançlar }\end{array}$ & Pozitif \\
\hline $\begin{array}{l}\text { Dong, Ryan ve } \\
\text { Zhang }\end{array}$ & 2014 & $\begin{array}{l}200 \text { banka, 1998- } \\
2006\end{array}$ & $\begin{array}{l}\text { Gelir ve giderlerin yeniden } \\
\text { sınıflandırılması }\end{array}$ & GUD uygulanması & Nötr \\
\hline Greiner & 2015 & $\begin{array}{l}257 \text { banka, 1542 } \\
\text { veri, 2005-2012 }\end{array}$ & $\begin{array}{l}\text { Menkul kıymetlerin net } \\
\text { gerçekleşen kazanç ve kayıpları }\end{array}$ & GUD uygulanması & Negatif \\
\hline $\begin{array}{l}\text { Bagna, Martino ve } \\
\text { Rossi }\end{array}$ & 2015 & $\begin{array}{l}120 \text { banka, 2008- } \\
2012\end{array}$ & $\begin{array}{l}\text { Finansal varlıkların değerindeki } \\
\text { indirimler }\end{array}$ & Seviye 3 & Pozitif \\
\hline $\begin{array}{l}\text { Filip, Jeanjean ve } \\
\text { Paugam }\end{array}$ & 2015 & $\begin{array}{l}38,667 \text { veri, 2003- } \\
2011\end{array}$ & Nakit akışlarındaki artış & GUD uygulanması & Pozitif \\
\hline $\begin{array}{l}\text { Choi, Mao ve } \\
\text { Upadhyay }\end{array}$ & 2015 & $\begin{array}{l}404 \text { firma, 1654 } \\
\text { veri, 1996-2006 }\end{array}$ & $\begin{array}{l}\text { Türev ürünlerin riskten } \\
\text { korunması }\end{array}$ & GUD uygulanması & Karma \\
\hline Pinto ve Pais & 2015 & 36 fon, 2002-2010 & Getiri dalgalanması & GUD uygulanması & Negatif \\
\hline Chen ve Gavious & 2016 & $\begin{array}{l}508 \text { şrket, 2001- } \\
2012\end{array}$ & $\begin{array}{l}\text { Gerçekleşmemiş kâr payı } \\
\text { ödemeleri }\end{array}$ & GUD uygulanması & Pozitif \\
\hline Hsu ve Lin & 2016 & 537 veri, 2007-2013 & Gerçekleşmemiş kazançlar & Seviye 3 & Pozitif \\
\hline $\begin{array}{l}\text { Couch, Thibodeau } \\
\text { ve Wu }\end{array}$ & 2017 & $\begin{array}{l}556 \text { banka, 2004- } \\
2012\end{array}$ & $\begin{array}{l}\text { Kazanç dalgalanması (faaliyet } \\
\text { kârındaki dalgalanma) }\end{array}$ & GUD uygulanması & Negatif \\
\hline
\end{tabular}




\begin{tabular}{|c|c|c|c|c|c|}
\hline $\begin{array}{l}\text { Kohlbeck, Smith ve } \\
\text { Valencia }\end{array}$ & 2017 & 687 veri, $2008-2010$ & $\begin{array}{l}\text { Sermaye rasyosu ve } \\
\text { gerçekleşmemiş kazanç }\end{array}$ & Seviye 3 & Pozitif \\
\hline $\begin{array}{l}\text { Black, Chen ve } \\
\text { Cussatt }\end{array}$ & 2018 & $\begin{array}{l}933 \text { firma, 2008- } \\
2015\end{array}$ & $\begin{array}{l}\text { GUD karşılaştırılabilirliği } \\
\text { (kapsamlı gelir/ortalama } \\
\text { toplam varlıklar) }\end{array}$ & Seviye 2 ve Seviye 3 & Karma \\
\hline $\begin{array}{l}\text { Robinson, Smith } \\
\text { ve Valencia }\end{array}$ & 2018 & $\begin{array}{l}266 \text { banka, 2007- } \\
2010\end{array}$ & $\begin{array}{l}\text { Sermaye rasyosu ve } \\
\text { gerçekleşmemiş kazanç }\end{array}$ & Seviye 3 & Pozitif \\
\hline Šodan & 2019 & $\begin{array}{l}1220 \text { banka, 2011- } \\
2016\end{array}$ & $\begin{array}{l}\text { Kazanç dalgalanması (net karın } \\
\text { standart sapması) }\end{array}$ & Seviye 1 & Negatif \\
\hline $\mathrm{Xu}$ & 2019 & $\begin{array}{l}503 \text { banka, 2009- } \\
2016\end{array}$ & İhtiyari kredi zarar karşılıkları & Seviye 2 ve Seviye 3 & Negatif \\
\hline Zhao & 2019 & $\begin{array}{l}118 \text { banka, 2001- } \\
2014\end{array}$ & $\begin{array}{l}\text { Seküritizasyon kazançları } \\
\text { Kredi zarar karşııkları }\end{array}$ & GUD uygulaması & Pozitif \\
\hline $\begin{array}{l}\text { DeFond, Hu, Hung } \\
\text { ve Li }\end{array}$ & 2020 & $\begin{array}{l}1654 \text { firma, 2002- } \\
2008\end{array}$ & $\begin{array}{l}\text { Net kar ve peşin ödemeler } \\
\text { arasındaki ilişki }\end{array}$ & GUD uygulanması & Negatif \\
\hline $\begin{array}{l}\text { Chen, Lo, Tsang ve } \\
\text { Zhang }\end{array}$ & 2020 & $\begin{array}{l}1.245 \text { şirket, 2007- } \\
2015\end{array}$ & $\begin{array}{l}\text { İsteğe bağlı tahakkuklar } \\
\text { Gerçekleşmemiş } \\
\text { kazan/kayıplar }\end{array}$ & GUD uygulanması & Pozitif \\
\hline $\begin{array}{l}\text { Lilien, Sarath ve } \\
\text { Yan }\end{array}$ & 2020 & $\begin{array}{l}122 \text { şirket, 2009- } \\
2012\end{array}$ & Pazarlıklı fiyat kazancı & Seviye 3 & Pozitif \\
\hline $\begin{array}{l}\text { Takacs, Szucs, Kehl } \\
\text { ve Fodor }\end{array}$ & 2020 & $\begin{array}{l}409 \text { banka, 2006- } \\
2018\end{array}$ & Ortalama kazanç kalitesi & GUD uygulanması & Negatif \\
\hline $\begin{array}{l}\text { Bratten, Causholli } \\
\text { ve Myers }\end{array}$ & 2020 & $\begin{array}{l}2.235 \text { veri, } 2000- \\
2008\end{array}$ & Kredi zarar karşıııkları & GUD kullanım ağırlığı & Karma \\
\hline Lin & 2021 & $\begin{array}{l}4208 \text { veri, } 2013- \\
2015\end{array}$ & Olağandışı kar ve zararlar & Seviye 3 & Pozitif \\
\hline $\begin{array}{l}\text { He, Wright ve } \\
\text { Evans }\end{array}$ & 2021 & 46 firma, 2001-2011 & Tarımsal kazanç değişimi & Seviye 3 & Pozitif \\
\hline $\begin{array}{l}\text { Wang, Qu, Du ve } \\
\text { Zhu }\end{array}$ & 2021 & $\begin{array}{l}9091 \text { veri, 2015- } \\
2018\end{array}$ & Hisse senedi rehin oranı & GUD uygulanması & Negatif \\
\hline
\end{tabular}

Çalışmaların en çok Amerika borsalarına kote şirketler üzerinde araştırma yaptıkları görülmektedir. Gerçeğe uygun değer ölçümünün ilk uygulamaları Amerika'da başlamış olup ilk sonuçları da burada görmek mümkündür. Bu durum geniş bir zaman aralığında inceleme yapma imkânını arttırmaktadır. Bunun yanında, bu şirketlerin finansal bilgilerine ulaşılabilecek veri tabanlarının geniş ve erişilebilir olması da çalışma yapmayı kolaylaştırmaktadır. Amerikan şirketlerini içeren örnekleri Çin'de faaliyet gösteren şirketler üzerinde yapılan çalışmalar takip etmektedir. Çin, gelişmekte olan ekonomiler içinde en yüksek pazar payına sahiptir. Bu çalışmalar, gelişmekte olan ülkelerin sonuçlarının gelişmiş ekonomilerde yer alan şirketlerin sonuçlarıyla karşılaştırma yapma imkânı vermesi bakımından önem taşımaktadır. Amerika ve Çin örneklerini Avrupa borsalarına kote şirketler takip etmektedir.

İncelenen 25 çalışmanın 10'u bankalar üzerinde araştırma yapmıştır. Bankalar ekonomi için kritik öneme sahip olmaları dolayısıyla kaliteli finansal raporlamaya en fazla ihtiyaç duyulan kuruluşlardır. Bunun yanında gerçeğe uygun değer ölçümünün en yaygın uygulama alanı finansal varlık ve yükümlülüklerin değerlemesinde görülmektedir. Bu nedenlerle bankacılık sektörü üzerinde yapılan çalışmalar önem taşımaktadır. Bankacılık sektörü uygulamaları incelendiğinde, gerçeğe uygun değer ve kazanç yönetimi arasındaki ilişki 5 çalışmada negatif yönlü olarak tespit edilmiştir. Grenier (2015) tarafından Amerikan bankaları üzerinde yapılan çalışmada, gerçeğe uygun değer ölçümünün uygulamasının kazançlar ve düzenleyici sermaye yönetimi üzerindeki etkisi araştırılmaktadır. Çalışmada gerçeğe uygun değer uygulayan ve uygulamayan bankalar iki ayrı gruba ayrılarak, kazanç yönetimi davranışlarındaki farklılıklar analiz edilmiştir. Çalışma bulguları, gerçeğe uygun değer uygulayan bankalarda kazançların ve sermayenin daha az yönetildiğini desteklemektedir. Benzer bir çalışma Couch, vd. (2017) tarafından yapılmıştır. Amerika'da borsaya kote bankalar ile yapılan analizde, gerçeğe uygun değer uygulamasının, faaliyet kârındaki değişim ile ölçülen kazanç dalgalanmasını azalttığı tespit edilmiştir. Kazanç dalgalanmasını net kârın standart sapması ile ölçen Šodan (2019) ise gerçeğe uygun değer hiyerarşisinin etkisini araştırmıştır. Çalışmada seviye 1 girdileri ile yapılan değerlemenin kazanç dalgalanmasını azalttığı yönünde bulgulara ulaşıımıştır. Takacs, vd. (2020) tarafından, 409 Avrupa bankası ile yapılan çalışmada, IFRS 13 öncesi ve sonrası dönem karşılaştırılmıştır. Çalışmada, IFRS 13'e geçişle birlikte artan gerçeğe uygun değerleme uygulamalarının kazanç kalitesini arttığı yönünde bulgulara ulaşılmıştır. Öte yandan, bankacılık sektörü örneklerini inceleyerek gerçeğe uygun değer ölçümünün kazanç yönetimini arttırdığına dair sonuçlar elde eden 4 çalışma bulunmaktadır. Bunlardan en eskisi Cheng (2012) tarafından gerçekleştirilmiştir. 886 banka ile yapılan çalışmada gerçeğe uygun değer raporlamasına geçişle, muhasebe takdir yetkisinin kullanımının arttığı tespit edilmiştir. Zhao, vd. (2019) da gerçeğe uygun değer ölçümüne geçişin etkisini araştırmıştır. Bankaların kredi kazanç karşlıklarını ve buna ikame olarak seküritizasyon 
kazançları yolu ile kazanç yönetimi yapıp yapmadığını araştıran çalışmada, risk düzeyi arttıkça kazanç üzerindeki takdir yetkisinin de arttığı tespit edilmiştir. Bagna, vd. (2015) ve Robinson, vd. (2018) ise seviye 3 ile yapılan ölçümün etkisini incelemiştir. Bagna, vd. (2015) tarafından Avrupa bankaları örnekleriyle yapılan çalışmada, Seviye 3 hiyerarşisinde sınıflandırılan likit olmayan finansal araçların gerçeğe uygun değerindeki İndirimlerin kazanç yönetimi kaynaklı olduğuna dair bulgular tespit edilmiştir. Robinson, vd.'nin (2018) araştırmasında ise Seviye 3 raporlayan işletmelerin sermaye rasyolarını artırmak için daha fazla gerçekleşmemiş kâr açıkladıkları tespit edilmiştir. Bankacılık sektörü örneklerini inceleyen bir diğer çalışma da Dong, vd. (2014) tarafından gerçekleştirilmiştir. Çalışmada bankaların, satışa hazır menkul kıymetlerin kazanç ve kayıplarının yeniden sınıflandırılması yolu ile kazanç yönetimi yapıp yapmadıkları araştırılmış, anlamlı bir ilişki bulunmamıştır.

Çalışma kapsamında incelenen 25 araştırmanın 15 tanesinde, gerçeğe uygun değer ölçümünün ya da gerçeğe uygun değer ölçümüne geçişin kazanç yönetimi üzerindeki etkisi araştırılmaktadır. Bunlardan bir bölümü gerçeğe uygun değer uygulamalarının başladığı yıl sonrası dönem ile başlamadan önceki dönemi karşılaştırırken, bir kısmı ise işletmeleri gerçeğe uygun değer ölçümü yapanlar ve yapmayanlar olarak sınıflandırarak analiz yapmıştır. Bratten, vd.'nin (2020) çalışmasında ise tüm varlık ve yükümlülükler içinde gerçeğe uygun değerin kullanım düzeyini baz alınmıştır. Kalan 10 çalışmada ise hiyerarşi seviyeleri kullanılarak araştırma yapılmıştır. Bu iki sınıflandırma (GUD uygulaması - hiyerarşi seviyesi) tüm araştırmaların bir bütün halinde yorumlanabilmesi için en anlamlı bilgiyi sunmaktadır. Araştırmalarında genel olarak gerçeğe uygun değer ölçümünün etkilerini konu alan 15 çalışmanın 6 tanesinde, gerçeğe uygun değer ölçümünün kazanç yönetimi uygulamalarını azalttığı tespit edilirken, 6 tanesinde ise attırdığına ilişkin bulgulara ulaşılmıştır. Bu sonuçların, örneklem seçimi, değişkenlerin ölçümü ve analiz yönteminden etkilenmiş olabileceği düşünülmektedir. Örneğin, He, vd. (2012) tarafından Çin'de borsaya kote işletme örnekleriyle yapılan araştırmada menkul kıymetlerde negatif gerçeğe uygun değer değişimi bildirenlerin, menkul kıymetleri satarak daha fazla kazanç beyan etme olasılıklarının, pozitif gerçeğe uygun değer değişikliği bildiren firmalardan daha fazla olduğu yönünde bulgulara ulaşılmıştır. Wang, vd. (2021) de Çin'de borsaya kote işletmeler ile araştırma yapmış, gerçeğe uygun değerin hisse senedi rehin oranı ile ölçülen kazanç yönetimi üzerindeki düzenleyici etkisinin daha fazla olduğu tespit edilmiştir. Chen ve Gavious (2016) tarafından gerçekleştirilen çalışma İsrail'de gerçeğe uygun değerin benimsenmesini takiben şirketlerin temettü politikasındaki değişiklikleri araştırmaktadır. Çalışmada hem gerçekleşmemiş kazanç üzerinden ödenen temettülerde hem de agresif vergi uygulamalarında gerçeğe uygun değer uygulaması sonrası önemli artış tespit edilmiştir. Ancak Pinto ve Pais (2015), Portekiz şirketlerinde gayrimenkul yatıım fonları yöneticilerinin gerçeğe uygun değer muhasebesi seçimlerinin kâr dağıtımları üzerindeki etkisi araştırmış ve gerçeğe uygun değer ölçümünün, yöneticilerin takdir yetkisini azaltmada yardımcı olacağına dair kanıtlar bulmuştur. 2 çalışmada ise karma sonuçlar elde edilmiştir. Örneğin, Choi, vd. (2015) tarafından S\&P 500'de işlem gören şirket ile yapılan araştırmada, FAS 133 riskten korunma muhasebesi standardının uygulanmasından sonraki dönemde türev ürünlerin riskten korunması ve isteğe bağlı tahakkuklar arasındaki ikame etkisinin düştüğü, ancak kazanç dalgalanmalarının arttığı tespit edilmiştir. Bratten, vd. (2020) tarafından yapılan çalışmada, daha yüksek gerçeğe uygun değer muhasebesi kullanan bankalarda kredi zarar karşılıkları yoluyla yapılan kazanç yönetiminin daha düşük olduğu, dönüşüm temelli (örneğin kar/zararın zamanlaması yoluyla) kazanç yönetimi uygulamalarının ise arttığı tespit edilmiştir.

Hiyerarşi seviyesi baz alınarak yapılan çalışmalar daha net bir sonuç sunmaktadır. 10 çalışmanın sadece 2 tanesinde gerçeğe uygun değerinin kazanç yönetimine etkisi negatiftir. Ancak, bunlardan ilki Šodan'ın (2019) çalışmasıdır ve bu çalışmada seviye 1 girdilerinin etkisi ölçülmektedir. Diğer çalışma ise Xu (2019) tarafından gerçekleştirilmiştir. Çalışmada seviye 2 ve seviye 3 girdi seviyelerinin ihtiyari kredi zarar karşılıkları üzerindeki etkisi analiz edilmiştir. Her iki seviyede de bulgular negatif olmakla birlikte, hiyerarşi seviyelerindeki artışla şeffaflığın azaldığı ve ihtiyariliğin arttığı tespit edilmiştir. Diğer tüm çalışmalarda ise (Bagna, vd., 2015; Hsu ve Lin, 2016; Kohlbeck, vd., 2017; Robinson, vd., 2018; Lilien, vd., 2020; Lin, 2021; He, vd., 2021) seviye 3 girdileri kullanılarak yapılan değerlemenin kazanç yönetimini arttırdığı tespit edilmiştir.

Çalışma sonuçları bir bütün olarak değerlendirildiğinde, incelenen 25 çalışmada gerçeğe uygun değerin kazanç yönetimini azalttığı sonucunu destekleyenlerin sayısı 8; arttırdığı yönünde bulgular elde eden çalışmaların sayısı ise 13'tür. Çalışmaların ağırlıklı sonucu pozitif yönlü ilişkiyi desteklemekle birlikte bunların 7 tanesi, seviye 3 girdilerinin etkilerini araştıran çalışmalardan oluşmaktadır. 3 çalışmada karma bulgulara ulaşıırken, 1 çalışmada ise anlamlı bir ilişki tespit edilmemiştir.

\section{SONUÇ}

Varlık ve yükümlülüklerin ilk edinimlerinde maliyet esasına göre değerlenmesi ile gerçeğe uygun değer arasında bir fark bulunmamaktadır. İlk edinim tarihindeki maliyet bedeli de gerçeğe uygun bir bedeli yansıtıyor olacaktır. Ancak zaman içinde, değişen ekonomik koşullar altında, maliyet esası ile değerlenen varlık ve yükümlülüklerin olmaları gereken değeri yansıtması ve finansal tablo kullanıcılarına doğru bilgi sunması ihtimali zayıf kalmaktadır. Bu nedenle, gerçeğe uygun değer, tartışmalı tahmin yöntemlerine rağmen, varlık ve yükümlülüklerin finansal tablolarda gerçeğe en yakın haliyle rapor edilmesi ihtiyacını en iyi karşılayan değerleme yöntemi olarak görülmektedir.

Literatür incelendiğinde, gerçeğe uygun değerin kazanç yönetimini teşvik edip etmediğine dair yapılan araştırmalarda net bir fikir birliğine varılmadığı görülmektedir. Bu çalışma kapsamında incelenen ampirik araştırmaların sonuçları da benzer bulgular vermektedir. Çalışmaların ağırlıklı kısmında gerçeğe uygun değerin kazanç yönetimi uygulamalarını arttırdığı tespit edilmiş 
olmakla birlikte, bu çalışmaların ağırıklı bölümü de seviye 3 girdileri ile yapılan değerleme sonuçlarına dayanmaktadır. Gerçeğe uygun değer kullanımını bir bütün olarak ele alan ve gerçeğe uygun değer öncesi ve sonrası dönemi karşılaştıran çalışmaların önemli bölümünde kazanç yönetiminin azaldığına dair kanıtlar elde edilirken, seviye 3 girdilerinin kullanımının etkisini araştıran hemen hemen tüm çalışmalarda, gerçeğe uygun değerin kazanç yönetimini desteklediği görülmektedir. Dolayısıyla, gerçeğe uygun değer bir bütün olarak düşünüldüğünde, kullanıcılara faydalı bilgiler sunarken, seviye 3 girdilerinin kullanımı nedeniyle kazanç yönetimine fırsat verdiği sonucu ortaya çıkmaktadır.

Gerçeğe uygun değer ve kazanç yönetimi ilişkisini ampirik olarak ele alan çalışmaların ağılıklı kısmı Amerika'da borsaya kote şirket örnekleri ile gerçekleştirilmektedir. Konuyu, Çin dışında, gelişmekte olan ülkelerdeki şirket örnekleri ile inceleyen çalışmaların sayısı ise yetersiz kalmaktadır. Gelecek çalışmalarda gelişmiş ve gelişmekte olan ülke örneklerini ampirik olarak karşılaştırılması literatüre faydalı bilgiler sunacaktır. Ayrıca, farklı varlık ve yükümlülüklerde gerçeğe uygun değer tespiti için kullanılan seviye girdileri de farkılık gösterebilmektedir. Örneğin finansal araçlar, yapıları itibariyle, ağırlıklı olarak seviye 1 ve seviye 2 girdileri ile ölçülebilmektedir. Ancak maddi duran varlıklar ya da yatırım amaçlı gayrimenkullerin ölçümünde kullanılacak etkin piyasa fiyatlarına ya da gözlemlenebilir diğer girdilere ulaşım imkânı çok daha kısıtıdır. Bu varlıkların değerlemesinde seviye 3 girdileri de önemli yer tutmaktadır. Bu nedenle, tüm varlık ve kaynak gruplarını içeren çalışmalarda, varlık ve kaynakların sınıflandırılarak ilişkinin ölçülmesi önem taşımaktadır. Bunun yanında, birçok çalışmada gerçeğe uygun değerin kazanç yönetimi üzerindeki etkisinin güçlü bir kurumsal yönetim yapısı ile hafifleyeceğine dair kanıtlar sunulmaktadır. Gelecek çalışmalarda işletmelerin kurumsal yapılarını gösteren değişkenlerin de analize dâhil edilmesi daha geniş bir çıkarım yapma olanağını arttıracaktır.

\section{KAYNAKÇA}

Adıgüzel, H. (2018). Muhasebe literatüründe kazanç yönetimi teknikleri. Muhasebe ve Vergi Uygulamaları Dergisi, 11(1), 63-76.

Bagna, E., Di Martino, G., Rossi, D. (2015). No more discount under enhanced fair value hierarchy. Applied Economics, 47(51), 5559-5582. https://doi.org/10.1080/00036846.2015.1054068

Bartov, E., Givoly, D., Hayn, C. (2002). The rewards to meeting or beating earnings expectations. Journal of accounting and economics, 33(2), 173-204.https://doi.org/10.1016/S0165-4101(02)00045-9

Black, J., Chen, J. Z., Cussatt, M. (2018). The association between SFAS No. 157 fair value hierarchy information and conditional accounting conservatism. The Accounting Review, 93(5), 119-144. https://doi.org/10.2308/accr-51963

Bratten, B., Causholli, M., Myers, L. A. (2020). Fair value exposure, auditor specialization, and banks' discretionary use of the loan loss provision. Journal of Accounting, Auditing \& Finance, 35(2), 318-348. https://doi.org/10.1177/0148558X17742567

Camphell, R.L., Owens-Jackson, L.A., Robinson, D. R. (2008). Fair Value Accounting From Theory to Practice. Strategic Finance, $90,31-37$.

Cebeci, Y., Gökçen, G. (2019). Gerçeğe uygun değer hiyerarşisine ilişkin Borsa İstanbul'da içerik analizi. Journal of Research in Business. 4 (2), 196-215. DOI: 10.23892/JRB.2019.61.

Chen, C., Lo, K., Tsang, D., Zhang, J. (2020). Understanding accounting discretion in China: An analysis of fair value reporting for investment property. Journal of Accounting and Public Policy, 39(4), 106766. https://doi.org/10.1016/j.jaccpubpol.2020.106766

Chen, E., Gavious, I. (2016). Unrealized earnings, dividends and reporting aggressiveness: an examination of firms' behavior in the era of fair value accounting. Accounting \& Finance, 56(1), 217-250.https://doi.org/10.1111/acfi.12187

Cheng, K. (2012). Accounting discretion and fair value reporting: a study of US banks' fair value reporting of mortgage-backedsecurities. Journal of Business Finance \& Accounting, 39(5-6), 531-566. https://doi.org/10.1111/j.1468-5957.2012.02288.x

Choi, J. J., Mao, C. X., Upadhyay, A. D. (2015). Earnings management and derivative hedging with fair valuation: Evidence from the effects of FAS 133. The Accounting Review, 90(4), 1437-1467. https://doi.org/10.2308/accr-50972

Couch, R., Thibodeau, N., Wu, W. (2017). Are fair value options created equal? A study of SFAS 159 and earnings volatility. Advances in accounting, 38, 15-29. https://doi.org/10.1016/j.adiac.2017.05.001

Dechow, P. M., Skinner, D. J. (2000). Earnings management: Reconciling the views of accounting academics, practitioners, and regulators. Accounting horizons, 14(2), 235-250. https://doi.org/10.2308/acch.2000.14.2.235

Dechow, P.M., Sloan, R.G., Sweeney, A.P. (1995). Detecting earnings management. The Accounting Review, 70(2), $193-225$.

DeFond, M., Hu, J., Hung, M., Li, S. (2020). The effect of fair value accounting on the performance evaluation role of earnings. Journal of Accounting and Economics, 70(2-3), 101341. https://doi.org/10.1016/j.jacceco.2020.101341

Degeorge, F., Patel, J., Zeckhauser, R.(1999). Earnings Management to Exceed Thresholds. The Journal of Business, 72(1), 1-33. https://www.jstor.org/stable/10.1086/209601

Demir, V., \& Bahadır, O. (2007). Muhasebe manipülasyonu-yöntemler ve teknikler. Mali Çözüm Dergisi, 84(6), 103-119. 
Dong, M., Ryan, S., Zhang, X. J. (2014). Preserving amortized costs within a fair-value-accounting framework: Reclassification of gains and losses on available-for-sale securities upon realization. Review of Accounting Studies, 19(1), 242-280.https://doi.org/10.1007/s11142-0139246-7

Fan, Y., Barua, A., Cready, W. M., Thomas, W. B. (2010). Managing earnings using classification shifting: Evidence from quarterly special items. The Accounting Review, 85(4), 1303-1323.https://doi.org/10.2308/accr.2010.85.4.1303

Filip, A., Jeanjean, T., Paugam, L. (2015). Using real activities to avoid goodwill impairment losses: Evidence and effect on future performance. Journal of Business Finance \& Accounting, 42(3-4), 515-554.https://doi.org/10.1111/jbfa.12107

Gandhi, K. (2018). Real Earnings Management: A Critical Review of Literature. Prajnan, 47(3). 255-283.

Ghio, A., Filip, A., Jeny, A. (2018). Fair value disclosures and fair value hierarchy: Literature review on the implementation of IFRS 13 and SFAS 157. Paris France: Autorité des Normes Compatables.

Goncharov, I., Riedl, E. J., Sellhorn, T. (2014). Fair value and audit fees. Review of Accounting Studies, 19(1), $210-241$. https://doi.org/10.1007/s11142-013-9248-5

Gökgöz, A., Şentürk, F. (2015). Borsa istanbul'da işlem gören şirketlerin gerçeğe uygun değer ölçümü. Journal of Accounting, Finance and Auditing Studies. 1(4), 67-80.

Greiner, A. J. (2015). The effect of the fair value option on bank earnings and regulatory capital management: Evidence from realized securities gains and losses. Advances in accounting, 31(1), 33-41. https://doi.org/10.1016/j.adiac.2015.03.005

Gunny, K. A. (2010). The relation between earnings management using real activities manipulation and future performance: Evidence from meeting earnings benchmarks. Contemporary Accounting Research, 27(3), 855-888.https://doi.org/10.1111/j.1911-3846.2010.01029.x

He, L., Wright, S., Evans, E. (2021). The impact of managerial discretion on fair value information in the Australian agricultural sector. Accounting \& Finance, 61, 1897-1930. https://doi.org/10.1111/acfi.12647

He, X., Wong, T. J., Young, D. (2012). Challenges for implementation of fair value accounting in emerging markets: Evidence from China. Contemporary Accounting Research, 29(2), 538-562. https://doi.org/10.1111/j.1911-3846.2011.01113.x

Healy, P. M., Wahlen, J. M. (1999). A review of the earnings management literature and its implications for standard setting. Accounting horizons, 13(4), 365-383.https://doi.org/10.2308/acch.1999.13.4.365

Hsu, A.W., Wu, G.S. (2019). The fair value of investment property and stock price crash risk. Asia-Pacific Journal of Accounting \& Economics, 26(1-2), 38-63. DOI: 10.1080/16081625.2019.1545895

Hsu, P. H., \& Lin, Y. R. (2016). Fair value accounting and Earnings Management. Eurasian Journal of Business and Management, 4(2), $41-54$.

Jones, J.J. (1991). Earnings management during import relief investigation. Journal of Accounting Research, 29(2),193-228.

Kohlbeck, M., Smith, T., Valencia, A. (2017). Auditors and net transfers of Level 3 fair-valued financial instruments. Advances in accounting, 36, 27-39.https://doi.org/10.1016/i.adiac.2016.09.003

Levitt Jr, A. (1998). The numbers game. The CPA Journal, 68(12), 14-19.

Lilien, S., Sarath, B., Yan, Y. (2019). Fair value accounting, earnings management, and the case of bargain purchase gain. Asian Review of Accounting, 28(2), 229-253. https://doi.org/10.1108/ARA-04-2018-0091

Lin, Y. T. (2021). Evidence on using the estimation of level 3 fair values as an earnings management tool: evidence from Taiwan. Review of Quantitative Finance and Accounting, 1-26. https://doi.org/10.1007/s11156-021-01009-9

McVay, S. E. (2006). Earnings management using classification shifting: An examination of core earnings and special items. The Accounting Review, 81(3), 501-531. https://doi.org/10.2308/accr.2006.81.3.501

Mulford, C. W., Comiskey, E. E. (2005). The financial numbers game: detecting creative accounting practices. John Wiley \& Sons.

Pinto, I., Pais, M. C. (2015). Fair value accounting choice: Empirical evidence from Portuguese real estate investment funds. Journal of European Real Estate Research. https://doi.org/10.1108/JERER-09-2014-0032

Robinson, D., Smith, T., Valencia, A. (2018). Does managerial opportunism explain the differential pricing of level 3 fair value estimates?. Journal of Financial Research, 41(2), 253-289. https://doi.org/10.1111/ifir.12146

Schipper, K. (1989). Commentary on Earnings Management, Accounting Horizons, 3(4), 91-102.

Senel, S. A., Tuncay, M., Önoğul, Ö., Karslı, C. (2011). Türkiye muhasebe standartlarında yer alan bir değerleme ölçüsü: gerçeğe uygun değer. E-Journal of New world Sciences Academy, 6(1), 48-76

Šodan, S. (2019). Fair value hierarchy and earnings volatility. Ekonomska misao i praksa, (2), 567-577.

Song, C. J., Thomas, W. B., Yi, H. (2010). Value relevance of FAS No. 157 fair value hierarchy information and the impact of corporate governance mechanisms. The Accounting Review, 85(4), 1375-1410. https://doi.org/10.2308/accr.2010.85.4.1375 
Takacs, A., Szucs, T., Kehl, D., Fodor, A. (2020). The effect of fair valuation on banks' earnings quality: empirical evidence from developed and emerging European countries. Heliyon, 6(12), e05659. https://doi.org/10.1016/j.heliyon.2020.e05659

TFRS 13. (2021). Türkiye Finansal Raporlama Standardı 13: Gerçeğe Uygun Değer Ölçümü. Erişim adresi: https://kgk.gov.tr/Portalv2Uploads/files/Duyurular/v2/TMS_TFRS_Setleri/2021/Mavi_Kitap/TFRS\%2013(1).pdf

Thesing, J., Velte, P. (2021). Do fair value measurements affect accounting-based earnings quality? A literature review with a focus on corporate governance as moderator. Journal of Business Economics, 965-1004. https://doi.org/10.1007/s11573-020-01025-6

Wang, W., Qu, X. H., Du, J. J., Zhu, J. M. (2021). The Influence of Fair Value Measurement on the Pledge of Overconfident Major Shareholders Based on Multiple Regression and Fisher Test. Complexity, 2021. https://doi.org/10.1155/2021/5578367

Xu, R. Z., Taylor, G. K., Dugan, M. T. (2007). Review of real earnings management literature. Journal of Accounting Literature, 26, 195-228.

$\mathrm{Xu}, \mathrm{X}$. (2019). The association between fair value measurements and banks' discretionary accounting choices. Advances in accounting, 44, 108-120. https://doi.org/10.1016/j.adiac.2018.12.007

Zhao, Q. (2019). Interaction between securitization gains and abnormal loan loss provisions: Credit risk retention and fair value accounting. Journal of Business Finance \& Accounting, 46(7-8), 813-842. https://doi.org/10.1111/jbfa.12381 